\title{
STRESS AND WOMEN
}

\author{
A.S.Sane ${ }^{1}$, V.V.Mishra' ${ }^{2}$ H.L Trivedi ${ }^{3}$ \\ Departments of Laboratory Medicine ${ }^{1}$, High Risk Pregnancy ${ }^{2}$, Director-Nephrology ${ }^{3}$. \\ Institute of Kidney Diseases and Research Centre, Civil Hospital Campus, Ahmedabad-380016, Gujarat, \\ India.
}

\begin{abstract}
Stress-tension-pain occur more often in health disorders of women than anywhere in the entire spectrum of human illness. No where is the effect of rapid change more apparent than in the changing role of today's women who are subjected to pressures from all sides. Now a days women virtually take part occupy positions, in day to day activities similar to their male counterparts. An outline of conceptual consideration, biochemical overview of stress and intricacies of coping mechanisms are delineated from the point of view of stress situations in female (during reproductive life span) peculiar to them only viz menarche, menstrual cycle, pregnancy eventualities of pregnancy-labour-delivery,purperium, postpartum psychosis, abortions-induced, spontaneous, menopause. Lipid profile and oxidative stress status as biochemical responses in these stresses were investigated. As expected observed maximal/minimal biochemical responses well correlated with peak time and at termination of stress. Present day emphasis is on menstrual regulation by intake of oral contraceptive to improve health if women prefer not to bleed every month and hormone replacement therapy for elderly women to improve post menopausal quality of life and avoiding menstrual problems at the same time.
\end{abstract}

KEY WORDS: Stress, female health.

\section{INTRODUCTION}

This review article begins with basics and conceptual considerations of phenomena of stress and subsequently deals with relevance of gender difference. Stress is natural, unavoidable feature and threat to quality of life, physical, psychological wellbeing of humans. (1) Hunting man was always under stress and present-day man is no way better. Somehow every human being is familiar with term stress. It can serve as useful stimulus (positive stress) yet excessive stress can lead to physical mental illness affecting individual's performance, loss of working hours, productivity, unnecessary economic burden in prevailing highly competitive working conditions. It may not be very easy to know

Address for correspondence:

Dr. A.S. Sane at the above address as to whether number of stressful events are on the increase in the present world but there are no indications that they are diminishing (2) Currently existing pattern of life style, urbanization leading to rapid social change, loss of cherished values, beliefs, breakdown of supportive social units, over crowding, population explosion, increase in violence, constant feeling of uncertainty, man made environmental pollution hazards have led to fear and stress situations distorting mental, physical health. The list of stress induced diseases is ever increasing viz. Hypertension, Ishaemic heart disease, gastrointestinal disturbance hyperacidity, indigestion, and malignancy. Stress is known to affect immune system immunosuppression immunological diseases (3). The role of stress is also appreciated in renal disorders from the present day environmental pollutants-contaminated drinking water heavy metals, pesticide containing 
food material, consumption of nephrotoxic drugs, infections, conditions altering hemodynamic status, hypertension and immunological problems. Now a days virtually most of the diseases are attributed to increased oxidative stress - free radical toxicity imbalance between oxidants and reducing agents (4).

Stress was defined by Selye (5) in his pioneering work as generalized nonspecific set of responses of the body (general adaption syndromefight, flight) primarily to protect organism from harm. Although stress is quantified by the individual perception, there may be considerable variation in individual physiologic response (stress as individual phenomena) (6). Stress, in essence, is a feeling of doubt about being able to cope, a perception that the resources available do not match the demands made(7). Now stress is defined as perceptual phenomena asrising from comparison between the demand on person and his or her's ability to cope which is both psychological (involving cognitive and behavioral) and physiological.

\section{Biochemical overview of stress}

It is now accepted that broad range of hormones endocrine systems concurrently respond to stress (8) a complex neuroendocrine affector effector response elicited by large number stimuli \{(stressors) exogenous/endogenous \} viz. fear, anxiety, physical trauma, pain, fever, hypo/ hyper thermia, malnutrition, infection, drugs- the perception of which involves activation of adrenergic cholinergic, serotonergic receptors in hypothalmus 'release of corticotrophin releasing factor (CRF) hypothalmopituitary, adrenomedullary and adrenocortical, so also pituitary, thyroid pituitary gonadal hormones secretions catechol amines adrenaline/noradrenaline, cortisol, peptides $\mathrm{GH}$, glucagon, insulin, vasopressin, angiotensinrenin aldosterone, testosterone interleukins, tumor necrosis factor and so forth. Initial endocrine response is to increase tissue catabolism (hyperglycemia, lipolysis muscle protein catabolism) due to increase in levels of ACTH, cortisol, $A D H, G H$, catecholamines (epi/norepi) rennin, angiotensin, aldosterone, glucagon, interleukin (IL1-8) and simultaneous decrease in insulin testosterone (9) and the level of these stress related hormones, peptides, biogenic amines is dependent not only on the length, magnitude of the stimulation but also on the type of stress experienced (10)

\section{Intricacies of coping mechanism}

Psychological and social stimuli are potent activators of stress response(11-12) and subsequently hypothalamopitutary adrenocortical (HPA) hypothalamo sympatho adrenomedullary axis (HAS) come into play. Research suggests that there are distinctive neuroendocrine responses that are preferred by the preexisting coping behavourial style. There is also evidence indicating that the kind of control (active avoidance versus passive/denial) used in coping with a given stress determines whether an adrenomedullary catecholamine response (favoring active control/ or adrenocortical corticosterone response (favoring passive control) is preferred (3). Specific dominance of one axis response over the other may determine the resulting affective/behavioral response to stressor. Some suggest that the amygdala is the locus of control of the active adrenomedullary response and the hippocampus septum is the control of the passive adrenocortical response (14). In addition stress response elicits release of opiods from the pituitary(endorphins, dynorphin and adrenal medulla (enkephalius) to modulate pain. Ancient Indian sages were known to make effective use of this.

\section{Guideline for keeping stress at minimal level}

In general it can be profitable to understand that one has to learn to accept the events as they occur with reasonable control on emotions to find out what is in your control and what is not, age matching optimal exercise, dietary modifications, behavioral reforms (tolerance) and better to adopt positive outlook towards life, minimal expectations and personal needs to tide over stress situations. Religion (faith), prayers, meditation are beneficial. 


\section{Stress and gender differences- why?}

Stress-tension -pain occurs more often in the health disorders of women than anywhere else in the entire spectrum of human illness (15). In many parts of the world women do not have access to information or services that might improve their reproductive health (16). No where is the effect of rapid change more apparent than in the changing role of today's woman who is subjected to pressures from all sides. Twentieth century offered number of gifts to the society like facilities equipments for day to comforts entertainments by way of scientific advances and at the same time man made stresses. One WHO survey has revealed females experience more psychological stresses in comparison with males. Conventionally in the typical Hindu family life right from ancient ages, woman has been depicted by patriarchal society as

$$
\begin{aligned}
& \text { कार्येषु मंत्री, भोजनेषु माता । } \\
& \text { शयनेषु रंभा चरणेषु दासी । }
\end{aligned}
$$

\section{Karyeshu Mantri, Bhojaneshu Maata Seyaneshu Rambha Charaneshu Daasi}

This well known "shloka" definitely glorifies the routine well known expected multiple roles that woman has to execute during her entire life span (viz-as daughter,sister, mother-married woman, additional family relationships culminating into innumerable expectational stresses.) If women pursue career, jobs for economic reasons/family comforts, occupy positions, involve in decision making similar to their male counterparts im addition to household commitments they must adept at balancing business and personal affairs with due collaboration from members of the family in order to have enough time for all demands made. The housewives of today also frequently question identity, honorableness of their work. The external stresses of so called modern civilized life style produce varying degrees of anxiety depending upon the nature and strength of stress and toughnessss/ appropriate individuals attitude (resistance) to overcome the situations. In underdeveloped world communities stresses are related to day to day very existence food shelter procreation etc. In developed countries stresses are man made social success, concept of status increased standard of living consumerism. Even then women in general are known to be efficient in facing the stresses of life in comparison with males probably due to reasonable reconciliation-adaptational -realistic attitudes.

However women are subject to stresses peculiar to them only though physiological at times trouble shooting depending upon their attitudes during reproductive lifespan-starting from menarche to menopause. Hence it was of interest to us to study biochemical response in terms serum lipid profile and oxidative stress status in different female stress situations.

Menarche the first menstrual flow which is the culmination of an orderly sequence of events taking place during puberty attributed to gradual transition from the pattern of hormone secretions characteristic of childhood to that of adulthood (17).

Menstruation in essence epitomizes puberty and recurs for rest of the reproductive life span recurrent reminding of femaleness. The four common disorders of the menstrual cycle are menorhaggia, irregularity period pain (premenstrual tension) amorrhagia and major culprit being emotional stress. A recent essay entitled 'Nuisance or natural and healthy: Should monthly menstruation be optional for women (18) from Lancet suggests menstrual control with contraceptives could improve women's health, concurrently a gain for society and women need not be driven loony by their lunar cycles if they prefer not to bleed every month. We studied menstrual cycle and serum lipid profile as biochemical response (19) in which maxima was encountered at ovulation day and minima on last day of menstruation ( $4^{\text {th }}$ or $5^{\text {th }}$ day) serving the guideline timing of physiological basal level.

Reproduction In woman's life pregnancy with all its positive aspects such as fulfillment of deepest and powerful desire, self realization, creative act is 
certainly known to be stressful period requiring adaptation to enable occurrence of growth and maturation (20). It is more stressful for primiparous women who face the challenges of pregnancy its eventualities $\sim$ labour $\sim$ delivery puerperum mothering for the first time(21). The pregnancy stress is partly due to conceptus induced adaptive, endocrinal subsequent metabolic changes and to some extent her psychological attitude.

Post partum psychosis another stress situation known to medical world since the time of Hippocrates[400BC] (22).

Abortion primarily as a measure of population control (thanks to gradual liberalization of abortion laws all over the world) continues to be an emotional, frustrating and stressful event. We studied abortion induced by hypertonic saline solution (23), by Emcredil and so also spontaneous abortion using serum lipoperoxide level as biochemical parameter (24).

Eclampsia/preeclampsia- hypertensive diseases in pregnancy constitute serious stress situation in some women and $50 \%$ of perinatal deaths in India are due to hypertension in pregnancy and it accounts for 5-20\% maternal death(25-26).

Menopause- the climacteric is a physiological consequence of ovarian failure and is associated with numerous biological effects-behavioral changes -some are short lived but do create unpleasantness. Hormonal changes occurring at the menopause are well recorded viz. increased levels of $\mathrm{FSH}, \mathrm{LH}$ low estradiol. At this phase of life they are at same risk level for heart attacks as males (increased serum lipid levels).

However in may parts of the world these days to improve post menopausal quality of life without incurring menstrual problem hormone replacement therapy (estradiol in low dose is advocated. Many experts believe that benefits of hormone replacement therapy may be greater than risks $(27-$ 28).

It is felt that stress at menarche, menstruation, pregnancy can be made tolerable, acceptable by inculcating positive attitude towards them as inevitable unavoidable features of femininity by providing useful counseling educational training since early life time by mothers, elderly women, mass media, social scientists family doctors. Gynecologists so that females can learn to modulate the levels of perception of these stresses and lead day to day activities normally and without any hindrance.

\section{Acknowledgement}

It is a pleasure to acknowledge technical assistance of Bela.P. Wadia Yazdi, and colleagues associated with human stress work- T.M.Chary, Shobha A Choksi, Ameeta K Pandya, S.R. Parikh, encouragement and blessings from $\mathrm{Dr}$. T.H Rindani, ex Medical Director Jaslok Hospital, Bombay.

\section{REFERENCES}

1. Tom Cox, Macay, C.J. (1976) Psychological model of Occupational stress, A Paper presented to medical research council meeting. Mental health in Industry, London. November.

2. Nakajima, H.(1994) Stress and Health, World health magazine 47(2), 2.

3. Calabrase, J.R., Kling, M.A. and Gold, P.W. (1987) Alterations in immunocompetence during stress, bereavement and depression: focuson neuroendocrine regulation. Amer. J. Psychiatry $144(9), 1123-1134$.

4. Halliwell, B. (1994) Free radicals, antioxidants and human diseases: Curiosity, cause or Consequence. Lancet $344,721-724$.

5. Selye, H. (1976) The stress of Life. New York: Mc Graw Hill Book Company.

6. Lazarus, R.S. (1966) Psychological stress and coping process. McGraw Hill N.Y. 
7. Bonn, D. and Bonn J. (2000) Work related stress: can it be a thing of past? Lancet 355,124 .

8. Mason, J.W.(1975) A historical view of the stress field J. Human Stress 1, 6-22.

9. Kessler, $R$, and Whalen, T. (1999) Hypnotic preparation in anesthesia and surgery in medical hypnosis Ed., Roberta Temes, Churchill Livingstone USA. p. 43-44.

10. Zinder,O.(1990) Biochemical overview of stress Clin. Chem. 36(6), 935.

11. Mason, J.W. (1968) A review of pyschoneuroendocrine research on the pitutary'adrenal cortical system. Psychosom. Med. 30, 576-607.

12. Dewied, D. and Jolles, J. (1982) Neuropeptides derived from pro-opiocortin: Behaviourial, physiological and neurochemical effects. Physiol. Rev. 62, 976-1059.

13. Bohus, B, Dekloet, E.R. and Veldhuis, H.D. (1982) Adrenal steroids and behaviourial adaptation: Relationship to brain corticoid receptors. In: Adrenal actions on Brain: Current topics in neuroendocrinology, Eds. Ganten, D. and Pfaff, D. Berlin Springer- Verlag, vol. 2, p. 107-148.

14. Henry, J.P. and Stephens, P. (1977) Stress Health and social environment. A socio biological approach to medicine. Springier, NewYork.

15. O'Neill, D. (1959) Stress and the female role. J. Obstet. \& Gyneecol. LX V1 (5), 762-790.

16. Chamberlain, G. and Simpkins, P.B. (2000) Practice of Obstetrics and Gynecology 3rd edn. Churchill Livingstone, London.

17. Chokshi, S.A. and Sane, A.S. (1985) Serum lipid profile at menarche. Pan Minerva Medica 27(3), 147-150.

18. Thomas, S.L. and Ellertson, C. (2000) Nuisance or natural and healthy: should monthly menstruation be optional for women? Lancet 355,922

19. Choksi, S.A. and Sane, A.S. (1981) Effect of menstrual stress on serum lipid levels. Experentia 37, 58-59.

20. Sane, A.S., Choksi, S.A., Chary T.M. and Parikh S.R. (1986) Effect of pregnancy stress on serum lipid levels .Ind. J.Clin Biochem. 1, 56-61.

21. Sane, A.S., Chary, T.M, Parikh, S.R. and Parikh K. (1983) Effect of labor stress on serum lipid levels. Pan Minerva Medica 25(1), 53-56.

22. Sane, A.S., Pandya, A.K., Patel, M.J. and Vaishnav, M.D. (1985) Serum cholesterol and triglycerides in post partum psychosis. Pan Minerva Medica 27(3), 143-146.

23. Sane, A.S., Choksi S.A. and Parikh, S.R. (1983) Les taux Des lipids seriques all course de l'avortement provoque' par une solution saline hypertonic (The levels of serum lipids during abortion induced by hypertonic saline solution) J. Gyn. Obstet. Biol. Repr. 12, 477-480.

24. Sane, A.S., Choksi S.A., Mishra, V.V., Barad, D.P., Shah, V.C. and Nagpal S. (1991) Serum lipoperoxides in induced and spontaneous abortions. Gynecol. Obstet. Invest. 31, 172-175.

25. Raman, L. (1988) Pregnancy hypertension: a challenge to obstetricians. Phys. Update 1(4), 164170.

26. Sane, A.S., Choksi, S.A., Mishra, V.V., Barad, D.P., Shah, V.C. and Nagpal, S. (1989) Serum lipoperoxide levels in pregnancy induced hypertension. Pan Minerva Medica 31(3), 119-122.

27. Greenberg, S. (1999) National Institute on Aging. Age Page: Hormone replacement therapy should you take it. March 8 th p. 1-4.

28. Spencer, C.P. (1999) Selective oestrogen receptor modulators, Women's panacea for the new millenium. Amer. J. Obstet. Gynaecol. 180, 763-770. 